\title{
Correction to: SGLT2 and cancer
}

\author{
Ernest M. Wright ${ }^{1}$
}

Published online: 21 September 2021

(c) Springer-Verlag GmbH Germany, part of Springer Nature 2021

\section{Correction to: Pflügers Archiv - European Journal of Physiology (2020) 472:1407-1414 https://doi.org/10.1007/s00424-020-02448-4}

The original publication contained an error in Figure 5 where the image showed Me4FDG PET, MRI and 2FDG scans on a control patient rather than those for the WHO grade IV astrocytoma patient described in the figure legend.

Fig. 5 Me4FDG PET, MRI, and 2FDG PET scans on a WHO grade IV astrocytoma patient. The 57-year-old male patient has a $46-\mathrm{mm}$ posterior corpus callosum astrocytoma. The Me-4FDG scan was conducted as for that on the control subject (Fig. 4) and shown as the $\mathrm{S} / \mathrm{N}$ (SUVR/BG) ratio relative to the torcula on the NIH color scale. The standard clinical 2FDG PET brain scan is for the "hot iron" on the SUVR based on a reference region of the brain. Taken from Kepe et al. (10).

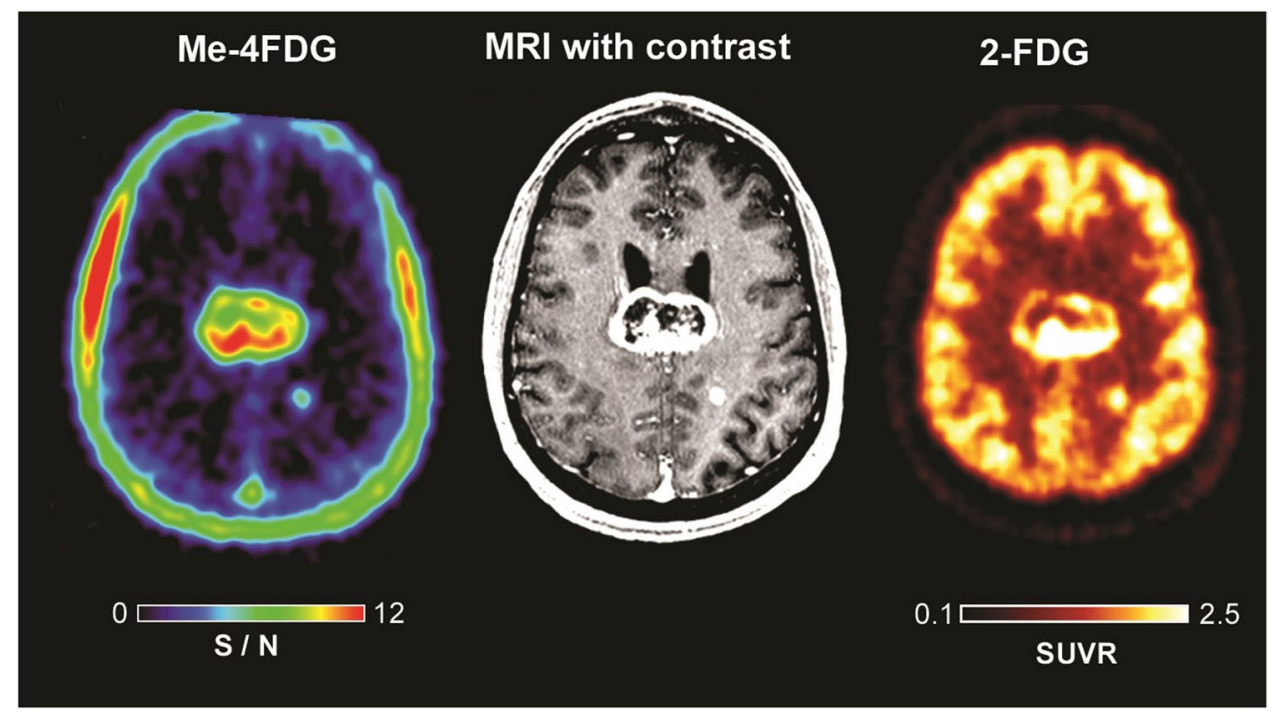

Publisher's note Springer Nature remains neutral with regard to jurisdictional claims in published maps and institutional affiliations.

The original article can be found online at https://doi.org/10.1007/ s00424-020-02448-4

Ernest M. Wright

Ewright@mednet.ucla.edu

1 Physiology Department, David Geffen School of Medicine at UCLA, Los Angeles, CA 90095-1751, USA 